\title{
BMJ Open A pre-postintervention study to evaluate the impact of dose calculators on the accuracy of gentamicin and vancomycin initial doses
}

\author{
Anas Hamad, ${ }^{1}$ Gillian Cavell, ${ }^{2}$ James Hinton, ${ }^{2}$ Paul Wade, ${ }^{3}$ Cate Whittlesea ${ }^{4}$
}

To cite: Hamad A, Cavell G, Hinton J, et al. A prepostintervention study to evaluate the impact of dose calculators on the accuracy of gentamicin and vancomycin initial doses. BMJ Open 2015;5:e006610.

doi:10.1136/bmjopen-2014006610

- Prepublication history for this paper is available online. To view these files please visit the journal online (http://dx.doi.org/10.1136/ bmjopen-2014-006610).

Received 11 September 2014 Revised 24 March 2015 Accepted 25 March 2015

CrossMark

\footnotetext{
${ }^{1}$ Institute of Pharmaceutical Science, King's College London, London, UK ${ }^{2}$ Pharmacy Department, King's College Hospital NHS Foundation Trust, London, UK

${ }^{3}$ Directorate of Infection, Guy's and St Thomas' NHS Foundation Trust, London, UK

${ }^{4}$ School of Medicine,

Pharmacy and Health, Durham University, Durham, UK
}

Correspondence to Anas Hamad; ahamad6@hamad.qa

\section{ABSTRACT}

Objectives: Gentamicin and vancomycin are narrowtherapeutic-index antibiotics with potential for high toxicity requiring dose individualisation and continuous monitoring. Clinical decision support (CDS) tools have been effective in reducing gentamicin and vancomycin dosing errors. Online dose calculators for these drugs were implemented in a London National Health Service hospital. This study aimed to evaluate the impact of these calculators on the accuracy of gentamicin and vancomycin initial doses.

Methods: The study used a pre-postintervention design. Data were collected using electronic patient records and paper notes. Random samples of gentamicin and vancomycin initial doses administered during the 8 months before implementation of the calculators were assessed retrospectively against hospital guidelines. Following implementation of the calculators, doses were assessed prospectively. Any gentamicin dose not within $\pm 10 \%$ and any vancomycin dose not within $\pm 20 \%$ of the guideline-recommended dose were considered incorrect.

Results: The intranet calculator pages were visited 721 times (gentamicin=333; vancomycin=388) during the 2month period following the calculators' implementation. Gentamicin dose errors fell from $61.5 \%$ (120/195) to $44.2 \%$ (95/215), $p<0.001$. Incorrect vancomycin loading doses fell from $58.1 \%(90 / 155)$ to $32.4 \%$ (46/ 142), $p<0.001$. Incorrect vancomycin first maintenance doses fell from $55.5 \%(86 / 155)$ to $33.1 \%(47 / 142)$, $p<0.001$. Loading and first maintenance vancomycin doses were both incorrect in $37.4 \%$ (58/155) of patients before and $13.4 \%$ (19/142) after calculator implementation, $p<0.001$.

Conclusions: This study suggests that gentamicin and vancomycin dose calculators significantly improved the prescribing of initial doses of these agents. Therefore, healthcare organisations should consider using such CDS tools to support the prescribing of these high-risk drugs.

\section{BACKGROUND}

Gentamicin and vancomycin are narrowtherapeutic-index antibiotics with potential

\section{Strengths and limitations of this study}

- This study suggests that accuracy of gentamicin and vancomycin initial doses can be improved using dose calculators linked to electronic prescribing.

- Dose improvements were demonstrated in multiple specialities within a large acute teaching hospital.

- Unlike previous studies, this study evaluated the accuracy of loading and first maintenance doses of vancomycin.

- This study did not assess the clinical and/or pharmacodynamic outcomes of the calculators.

- It was not possible to identify whether individual doctors who accessed the calculators used the tool for calculating drug doses prior to prescribing.

- The use of different methods to identify patients precalculators and postcalculators may have led to differences in patient demographics.

- The long-term impact of the calculators (eg, 12 months postimplementation) was not assessed in this study.

for high toxicity and require dose individualisation with regular therapeutic drug monitoring. The main side effects of gentamicin are dose-related, and include nephrotoxicity and irreversible ototoxicity, while the main side effects of parenteral vancomycin, not necessarily dose-related, include nephrotoxicity, normally-reversible ototoxicity and blood disorders including neutropenia. ${ }^{1}$

Antibiotics were the most common medications associated with prescribing errors $(39.7 \%$, 276/696) in a US study. Overdosing and underdosing accounted for $58.3 \%$ of these errors $(406 / 696) .^{2}$ Gentamicin and vancomycin are often poorly prescribed, and dosing errors are a particular problem. Underdosing may lead to treatment failure while overdosing can cause toxicity. An Australian study showed that only $30.3 \%$ (40/132) of all gentamicin initial doses were in accordance with hospital guidelines. ${ }^{3}$ 
Another Australian study found that of 60 eligible gentamicin initial doses, only $46.7 \% \quad(n=28)$ were consistent with local guidelines. ${ }^{4}$ A US study conducted in a tertiary-care hospital identified that only $50.6 \%(128 / 253)$ of vancomycin initial doses were appropriate according to national guidelines. ${ }^{5}$ Fuller et at found that only $22.1 \%(980 / 4441)$ of all vancomycin doses prescribed at a US emergency department (ED) were correct as per national guidelines.

Narrow-therapeutic-index medications are more likely to cause adverse drug events (ADEs) and may be more prone to medication errors. Clinical decision support (CDS) may therefore be of particular value for these high-risk medications. ${ }^{7}$ A number of CDS tools have been shown to be effective in reducing gentamicin/ vancomycin dosing errors. One of these tools, 'Pharmacist-to-Dose', a computerised request sent by the prescriber to the pharmacist for dosing guidance on vancomycin and aminoglycosides, was evaluated by Vincent $e t$ al. This tool significantly reduced medication errors with these drugs $(31.6 \%, 18 / 57$ vs $7.0 \%, 5 / 71$, $\mathrm{p}=0.002) .{ }^{7}$ Another CDS tool, GFR+, automatically calculates and updates doses of key drugs based on renal function. When evaluated by Roberts et $a l^{8}$ this tool improved dosing conformity for both gentamicin $(63 \%$, $46 / 73$ vs $87 \%, 33 / 38, \mathrm{p}=0.01)$ and vancomycin $(47 \%$, $16 / 34$ vs $77 \%, 13 / 17, \mathrm{p}=0.07$ ).

Other CDS tools were not effective in reducing gentamicin/vancomycin dosing errors. Some were even potentially harmful. One CDS tool was a computerised prescriber order entry (CPOE) system that displayed an initial default dose for gentamicin and tobramycin in the dose box on the electronic prescription. In a large proportion $(58 \%, 227 / 392)$ of prescriptions, the suggested default dose had not been amended. This dose was used in $51.6 \%(132 / 256)$ of prescriptions for renal-insufficiency patients and $85.6 \%$ (113/132) of these resulted in potential ADEs compared with 53.2\% $(66 / 124)$ for the remaining prescriptions $(p<0.0001)$. For patients without renal impairment, use of the CDS tool to determine doses was not significantly better than regular dosing. The dose was incorrect in $72.7 \%$ (165/ $227)$ of CDS prescriptions compared to $77 \%(127 / 165)$ in non-CDS prescriptions $(\mathrm{p}=0.4)$. Therefore, this tool was a source of potential ADEs especially in renalinsufficiency patients. ${ }^{9}$

Risks with gentamicin and vancomycin were identified locally in a number of ways. An analysis of antibioticassociated medication incidents reported to the centralised incident reporting systems of two large UK teaching hospitals, including the study site, over 2 years, was undertaken. ${ }^{10}$ One-third of dose/frequency errors reported $(32 / 96)$ at the study site were related to gentamicin $(n=16)$ and vancomycin $(n=16)$. A local Failure Modes and Effects Analysis for gentamicin identified that risks with dose calculation and prescribing, especially in patients with renal impairment or obesity, were greater than risks with preparation of infusions. The implementation of electronic prescribing across the hospital facilitated the development of computerised dose calculators for these drugs to improve prescribing, championed by the Lead Antimicrobial Pharmacist with the support of the Antibiotic Usage Steering Group.

The aim of this study was to evaluate the impact of these calculators on the accuracy of prescribing of gentamicin and vancomycin initial doses.

\section{METHODS}

\section{Study design}

The study used a pre-postintervention design and was undertaken at a 950-bed acute National Health Service (NHS) teaching hospital in London. Prescriptions for gentamicin initial dose and vancomycin initiation regimen (loading dose and first maintenance dose) written during the 8-month period (1 January 2011-31 August 2011) before implementation of the dose calculators were retrospectively assessed for appropriateness. Following implementation of gentamicin and vancomycin dose calculators, and promotion throughout the hospital, data on the appropriateness of prescriptions for their initial doses were collected prospectively for a 2-month period (1 June 2013-2 August 2013). In addition to loading doses, first maintenance doses were assessed as part of vancomycin initiation regimens. This was considered important, as the first maintenance dose is essential in ensuring appropriate serum levels, and that is reflected in that the new calculator provides both loading and first maintenance doses.

The study was categorised by the hospital Research and Development Department as a clinical audit/service evaluation. Thus, ethical approval was not required. However, the study was registered with the Clinical Effectiveness and Audit Department.

\section{Inclusion/exclusion criteria}

All adults without severe renal impairment (creatinine clearance $(\mathrm{CrCl}) \geq 20 \mathrm{~mL} / \mathrm{min}$ and not receiving haemo/peritoneal dialysis) who received parenteral gentamicin or vancomycin (loading and at least one maintenance dose) were included in this study. Patients who received gentamicin as antibiotic prophylaxis prior to urinary catheterisation, and patients receiving gentamicin as part of a two times or three times/day endocarditis treatment regimen were excluded. Patients who received vancomycin as an oral dose, once-only intravenous dose, or continuous infusion were also excluded. Patients without recorded height and weight were excluded, as these criteria are essential for calculating ideal body weight (BW) required for dose calculation; also excluded were those with a height less than

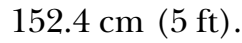

\section{Definitions}

Incorrect doses of gentamicin and vancomycin have been described in the literature as doses outside the ranges of $10 \%^{9}$ and $33.3 \% .^{8}$ For the purposes of this 
study, an incorrect dose of gentamicin was defined as 'any dose more than $10 \%$ higher or lower than the recommended dose as specified in the hospital guidelines'. An incorrect dose of vancomycin was defined as 'any dose more than 20\% higher or lower than the recommended dose as specified in the hospital guidelines'. These margins were chosen taking into account that gentamicin and vancomycin have a narrow therapeutic index and that many patients receiving these drugs have some element of renal-insufficiency. They also consider that doses are usually rounded based on the available dosage forms and the practicalities of dose administration.

\section{Sample size calculation}

In order to perform power and sample size calculations, data were collected retrospectively for 49 patients who received (both prescribed and administered) gentamicin and for 36 patients who received vancomycin. A power analysis conducted using assumptions of $95 \%$ power identified that at each stage preintervention and postintervention, a minimum sample of 192 patients who received gentamicin and a minimum sample of 141 patients who received vancomycin were required to detect a $30 \%$ reduction in error incidence with each drug.

\section{Study intervention}

Calculators for gentamicin and vancomycin doses were implemented in the hospital as an Excel application on the hospital intranet. This is accessed by users from a menu within the Electronic Prescribing and Medicines Administration system (EPMA) of the Electronic Patient Records (EPR) iSOFT Clinical Manager, which gives access to patient demographics, hospital visit histories, clinical notes, laboratory results and drug prescribing and administration records. Prescribers are directed to the calculators through a written note within the electronic prescription for each drug. The calculators are not automatically populated from demographic or laboratory data entered elsewhere within EPR. The calculator uses patient information manually entered by the prescriber, including age, actual BW, height and serum creatinine $(\mathrm{SrCr})$ to provide the appropriate dose and frequency for each patient based on their weight and $\mathrm{CrCl}$. These calculators can be used with either metric or imperial units, and are gender-specific. Once required data are entered, the calculator will automatically determine the appropriate weight to be used (actual, ideal or adjusted), $\mathrm{CrCl}$, recommended dose (loading and first maintenance for vancomycin), recommended dosing interval and duration of vancomycin infusion (to avoid possible Red man syndrome). The dose given by the calculator is the dose recommended by the hospital antimicrobial guidelines. ${ }^{11}$

The hospital antimicrobial guidelines include instructions for dosing gentamicin and vancomycin. Ideal BW should be used for dosing and $\mathrm{CrCl}$ calculation, unless the patient is underweight (below ideal BW) when actual $\mathrm{BW}$ is used or overweight (actual $\mathrm{BW}>20 \%$ over ideal BW) when adjusted BW is used. Estimated BW can only be used when other options are not available. The initial gentamicin dose is calculated depending on patient's appropriate weight and $\mathrm{CrCl}$, which is calculated using the Cockcroft-Gault equation. ${ }^{12}$ Although there are more accurate methods (eg, insulin clearance ${ }^{13}$ ), it is the method recommended by the hospital guidelines for routine measurement of renal function. The loading dose of vancomycin is calculated based on actual BW. If the patient is 'unfit' to be weighed, ideal BW is used, unless the patient looks underweight, in which case estimated BW is used. Vancomycin first maintenance dose is calculated based on the patient's appropriate weight and CrCl. Details of equations and calculations used in the calculators are in table 1.

\section{Calculator implementation}

On 1 September 2011, the calculators were first available on the hospital intranet. The calculators were promoted locally by pharmacists in specific clinical areas, particularly in haematology/oncology, where gentamicin is widely prescribed for the treatment of neutropenic sepsis. In February 2013, a link was created between EPMA and the relevant page on the intranet, enabling prescribers to access the required calculator on the same screen as the EPR. Junior doctors joining the hospital in February 2013 were informed about the calculators during their induction programmes for safe prescribing.

In May 2013, a non-mandatory instruction to use the calculator was added to gentamicin and vancomycin orders on EPMA, and the availability of the calculators was advertised on the intranet news page and via an email to all doctors. Moreover, information about the calculators and how to use them, as well as the precalculator results, were presented at one of the hospital Grand Rounds to encourage their use.

\section{Data collection and processing}

Data were collected using EPR (iSOFT Clinical Manager 1.4). Paper notes were also reviewed, if necessary, to collect data not available within EPR (eg, missing weight or height). A data collection form was developed, piloted and optimised before formal data collection started. Demographic data collected for each patient included age, gender, weight, height, $\mathrm{SrCr}$, clinical specialty and ward. Patients' body mass index (BMI) was also calculated. Details collected about antibiotic therapy included the first dose for gentamicin, and the loading and first maintenance doses for vancomycin. Dose frequency was also documented. Doses were compared with the hospital antibiotic guidelines valid at the time of prescribing. If patient height was not recorded on electronic or paper notes, patients were asked about their height. If patients were able to self-report their height, this height was used in the study. Estimated weights and heights were used if they were recorded in patient notes (eg, for critical-care patients). 
Table 1 Equations/calculations used in gentamicin and vancomycin dose calculators

\begin{tabular}{|c|c|c|c|c|c|c|}
\hline Variable & \multicolumn{6}{|c|}{ Underlying equation/calculation } \\
\hline Ideal body weight $(\mathrm{kg})^{14}$ & \multicolumn{6}{|c|}{$\begin{array}{l}\text { With height in feet/inches }=\text { [males } 50 \mathrm{~kg} \text {, females } 45.5 \mathrm{~kg}]+2.3 \mathrm{~kg} \text { for every inch in height } \\
\text { over } 5 \mathrm{ft} \\
\text { With height in centimetres }=\text { [male } 50 \mathrm{~kg} \text {, female } 45.5 \mathrm{~kg}]+[(2.3 \times \text { height in } \mathrm{cm} \text { above 152.4)/ } \\
2.54 \text { ] }\end{array}$} \\
\hline \multirow{3}{*}{$\begin{array}{l}\text { Adjusted body weight } \\
(\mathrm{kg})^{15 *} \\
\text { Creatinine clearance } \\
(\mathrm{mL} / \mathrm{min})^{12}\end{array}$} & \multirow{2}{*}{\multicolumn{6}{|c|}{$\begin{array}{l}=\text { ideal body weight }(\mathrm{kg})+0.4[(\text { actual body weight }(\mathrm{kg}) \text {-ideal body weight }(\mathrm{kg})] \\
=\frac{140-\text { Age }(\text { years }) \times \text { Weight }(\mathrm{kg}) \times \mathrm{F}}{\text { Serum creatinine }(\mu \mathrm{mol} / \mathrm{L})} \quad \mathrm{F}=1.04 \text { for females and } 1.23 \text { for males }\end{array}$}} \\
\hline & & & & & & \\
\hline & $\mathrm{CrCl}(\mathrm{mL} / \mathrm{min})$ & \multicolumn{5}{|c|}{ Dose and dosing interval } \\
\hline \multirow[t]{6}{*}{ Gentamicin initial dose $^{11}$} & $>80$ & \multicolumn{5}{|c|}{$5.0 \mathrm{mg} / \mathrm{kg}$ every $24 \mathrm{~h}$} \\
\hline & $60-80$ & \multicolumn{5}{|c|}{$4.0 \mathrm{mg} / \mathrm{kg}$ every $24 \mathrm{~h}$} \\
\hline & $40-60$ & \multicolumn{5}{|c|}{$3.5 \mathrm{mg} / \mathrm{kg}$ every $24 \mathrm{~h}$} \\
\hline & $30-40$ & \multicolumn{5}{|c|}{$2.5 \mathrm{mg} / \mathrm{kg}$ every $24 \mathrm{~h}$} \\
\hline & 20-30 & \multicolumn{5}{|c|}{$4.0 \mathrm{mg} / \mathrm{kg}$ every $48 \mathrm{~h}$} \\
\hline & $\begin{array}{l}\text { Actual body } \\
\text { weight (kg) }\end{array}$ & $<60$ & $60-90$ & $>90$ & & \\
\hline \multirow{5}{*}{$\begin{array}{l}\text { Vancomycin loading } \\
\text { dose }^{11} 16\end{array}$} & Loading dose & $1000 \mathrm{mg}$ & $1500 \mathrm{mg}$ & 2000 & & \\
\hline & $\begin{array}{l}\text { Fluid }(\mathrm{NaCl} \text { or } \\
\text { glucose) }\end{array}$ & $250 \mathrm{~mL}$ & $500 \mathrm{~mL}$ & $500 n$ & & \\
\hline & Infusion period & $120 \min$ & $180 \mathrm{~min}$ & $240 n$ & & \\
\hline & Pump rate & $125 \mathrm{~mL} / \mathrm{h}$ & $167 \mathrm{~mL} / \mathrm{h}$ & $125 n$ & & \\
\hline & $\begin{array}{l}\mathrm{CrCl} \\
(\mathrm{mL} / \mathrm{min})\end{array}$ & $\begin{array}{l}\text { Dose } \\
(\mathrm{mg})\end{array}$ & $\begin{array}{l}\text { Dosing } \\
\text { interval (h) }\end{array}$ & $\begin{array}{l}\text { Fluid } \\
\text { (mL) }\end{array}$ & $\begin{array}{l}\text { Infusion } \\
\text { period } \\
\text { (min) }\end{array}$ & $\begin{array}{l}\text { Pump rate } \\
\text { (mL/h) }\end{array}$ \\
\hline \multirow{7}{*}{$\begin{array}{l}\text { Vancomycin maintenance } \\
\text { dose }^{11} 16\end{array}$} & $>110$ & 1500 & 12 & 500 & 180 & 167 \\
\hline & $90-110$ & 1250 & 12 & 250 & 150 & 100 \\
\hline & $75-89$ & 1000 & 12 & 250 & 120 & 125 \\
\hline & $55-74$ & 750 & 12 & 250 & 90 & 167 \\
\hline & $40-54$ & 500 & 12 & 250 & 60 & 250 \\
\hline & 30-39 & 750 & 24 & 250 & 90 & 167 \\
\hline & $20-29$ & 500 & 24 & 250 & 60 & 250 \\
\hline
\end{tabular}

In the precalculator phase of the study, patients who received gentamicin or vancomycin were identified retrospectively from the Microbiology database of patients for whom a gentamicin or vancomycin serum level had been requested. A random sample of gentamicin initial doses and a random sample of vancomycin initiation regimens that were prescribed during the 8 months prior to implementing the calculators were assessed against the guidelines for accuracy. In the postcalculator phase, patients were identified prospectively through an electronic filter of all active antimicrobial prescriptions. This filter was checked daily, and any patient who was prescribed gentamicin and/or vancomycin was reviewed on EPMA (and paper notes if necessary) for eligibility. During the 2 months following promotion of the calculators, the accuracy of gentamicin initial doses and vancomycin initiation regimens were assessed for all eligible patients (figure 1).

Data were transferred into SPSS, which was used for analysis. Quality-assurance procedures were undertaken to assure the quality and accuracy of the data transferred.
The correct dose was calculated for each patient based on hospital guidelines. Then, the difference between the prescribed dose and the calculated dose was determined. Based on its deviation from the guideline-recommended dose, each dose was categorised as an underdose $(>10 \%$ under for gentamicin and $>20 \%$ under for vancomycin), overdose $(>10 \%$ over for gentamicin and $>20 \%$ over for vancomycin), or correct dose $(\leq 10 \% \pm$ for gentamicin and $\leq 20 \% \pm$ for vancomycin). Data on number of times the intranet calculator pages were visited were provided by the hospital senior Web Developer.

\section{Data analysis}

Statistical data analysis was performed using SPSS V.21. Binary logistic regression was used to assess the significance of the difference between the number of correct doses, overdoses and underdoses, before and after implementation of the calculators. It was also used to produce ORs for these results. $\chi^{2}$ Analysis and Fisher's exact test were used to assess the significance of the difference between the patients' gender, ethnicity and 


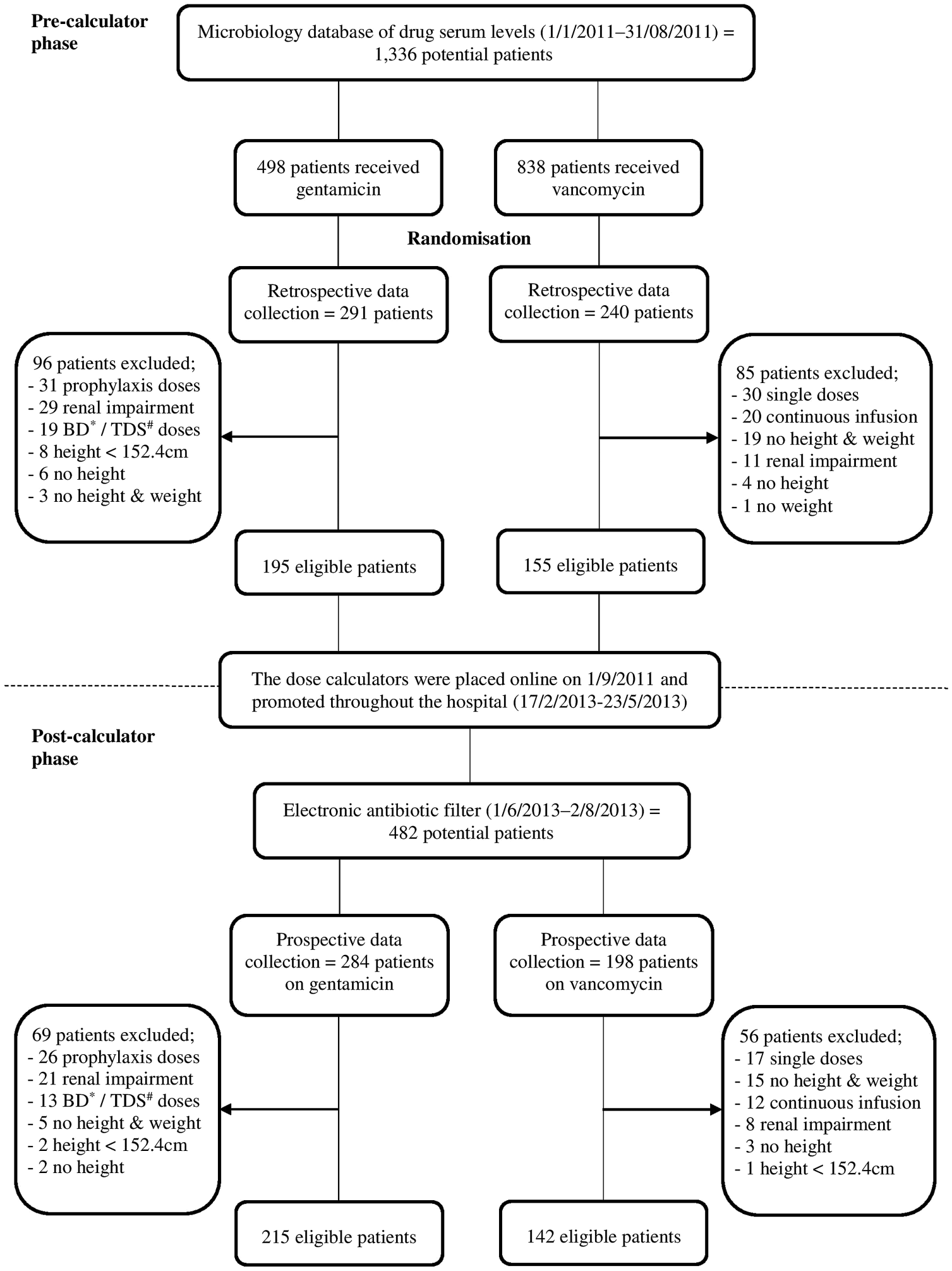

* Twice daily; ${ }^{*}$ Three times daily

Figure 1 Study participant flow chart.

prescriber specialty, before and after the calculators' implementation. The same tests were also used to measure the significance of the difference between the number of correct doses among different patient groups before and after the calculators. Two-sample t test was used to evaluate the difference in the age, BMI and $\mathrm{CrCl}$ of patients, before and after the calculators. The level of significance was chosen as $5 \%$. 
Table 2 Demographic data for included patients

\begin{tabular}{|c|c|c|c|c|c|c|}
\hline Category & $\begin{array}{l}\text { Gentamicin } \\
\text { before (\%) } \\
n=195\end{array}$ & $\begin{array}{l}\text { Gentamicin } \\
\text { after (\%) } \\
n=215\end{array}$ & p Value & $\begin{array}{l}\text { Vancomycin } \\
\text { before }(\%) \\
n=155\end{array}$ & $\begin{array}{l}\text { Vancomycin } \\
\text { after (\%) } \\
n=142\end{array}$ & p Value \\
\hline \multicolumn{7}{|l|}{ Gender } \\
\hline Male & $117(60.0)$ & $97(45.1)$ & 0.003 & $87(56.1)$ & $81(57.0)$ & 0.907 \\
\hline Female & $78(40.0)$ & $118(54.9)$ & & 68 (43.9) & $61(43.0)$ & \\
\hline Age $\pm S D$ (years) & $55.4 \pm 17.3$ & $57.6 \pm 18.5$ & 0.211 & $60.5 \pm 17.3$ & $57.7 \pm 16.6$ & 0.159 \\
\hline$B M I \pm S D\left(k g / m^{2}\right)$ & $25.8 \pm 6.0$ & $26.2 \pm 6.0$ & 0.546 & $26.4 \pm 45.9$ & $27.9 \pm 6.5$ & 0.030 \\
\hline $\mathrm{CrCl}_{ \pm} \mathrm{SD}(\mathrm{mL} / \mathrm{min})$ & $97.3 \pm 51.7$ & $90.6 \pm 48.2$ & 0.176 & $84.6 \pm 42.4$ & $100.7 \pm 43.0$ & 0.001 \\
\hline \multicolumn{7}{|l|}{ Ethnicity } \\
\hline White & 133 (68.2) & $144(67.0)$ & 0.833 & $100(64.5)$ & $106(74.6)$ & 0.060 \\
\hline Black & $37(19.0)$ & 49 (22.8) & 0.396 & $30(19.4)$ & $28(19.7)$ & 1.000 \\
\hline Asian & $10(5.1)$ & $13(6.0)$ & 0.831 & $6(3.9)$ & $5(3.5)$ & 1.000 \\
\hline Other & $7(3.6)$ & $4(1.9)$ & 0.364 & $8(5.2)$ & $2(1.4)$ & 0.107 \\
\hline Not specified & $8(4.1)$ & $5(2.3)$ & 0.400 & $11(7.1)$ & $1(0.7)$ & 0.006 \\
\hline \multicolumn{7}{|l|}{ Specialty } \\
\hline $\begin{array}{l}\text { Haematology/ } \\
\text { oncology }\end{array}$ & $99(50.8)$ & $55(25.6)$ & $<0.001$ & $39(25.2)$ & $16(11.3)$ & 0.003 \\
\hline Critical care & $45(23.1)$ & $24(11.2)$ & 0.001 & $10(6.5)$ & $3(2.1)$ & 0.089 \\
\hline Medicine & $16(8.2)$ & 65 (30.2) & $<0.001$ & $44(28.4)$ & $46(32.4)$ & 0.528 \\
\hline Surgery & $14(7.2)$ & 27 (12.6) & 0.073 & 22 (14.2) & 27 (19.0) & 0.277 \\
\hline Liver & $8(4.1)$ & 7 (3.3) & 0.794 & $15(9.7)$ & $13(9.2)$ & 1.000 \\
\hline Women/child & $6(3.1)$ & $18(8.4)$ & 0.033 & $1(0.6)$ & $2(1.4)$ & 0.608 \\
\hline Renal & $3(1.5)$ & $1(0.5)$ & 0.350 & $0(0)$ & $0(0)$ & - \\
\hline Neuroscience & $3(1.5)$ & $13(6)$ & 0.021 & $14(9.0)$ & $25(17.6)$ & 0.038 \\
\hline Cardiology & $1(0.5)$ & $5(2.3)$ & 0.219 & $10(6.5)$ & $10(7.0)$ & 1.000 \\
\hline
\end{tabular}

\section{RESULTS}

In total, 707 patients were included in the study; 410 received gentamicin (195 before and 215 after the calculator implementation) and 297 received vancomycin (155 before and 142 after the calculator implementation). While Haematology/Oncology were overall the most frequent prescribers of gentamicin $(37.6 \%$, $\mathrm{n}=154$ ), Medicine was the specialty in which vancomycin was most frequently prescribed $(30.3 \%, \mathrm{n}=90)$. Further details in table 2.

The gentamicin calculator page on the hospital intranet was visited 333 times during the 2-month period following implementation of the calculator. Correct gentamicin doses increased from $38.5 \%$ (75/195) before to $55.8 \%(120 / 215)$ after the calculator implementation, $\mathrm{OR}=2.02, \mathrm{p}<0.001$ (table 3 ).

The vancomycin calculator page on the hospital intranet was visited 388 times in the post calculator data collection period. Correct vancomycin loading doses increased from $41.9 \%(65 / 155)$ before to $67.6 \%$ (96/ 142) after the calculator implementation, $\mathrm{OR}=2.89$, $\mathrm{p}<0.001$. Correct vancomycin first maintenance doses increased from $44.5 \%(69 / 155)$ to $66.9 \%$ (95/142), $\mathrm{OR}=2.52, \mathrm{p}<0.001$. The whole vancomycin initiation regimen was correct (both loading and first maintenance doses were correct) in $23.9 \%(37 / 155)$ of patients before and $47.9 \%(68 / 142)$ after the calculator implementation, $\mathrm{OR}=2.93, \mathrm{p}<0.001$ (table 4).

The vancomycin initiation regimen was considered incorrect in three scenarios: loading dose is correct and first maintenance dose is incorrect: $18.1 \%$ before (28/ $155)$ and $19.7 \%$ after (28/142) implementation of the calculator; loading dose is incorrect and first maintenance dose is correct: $20.6 \%$ before (32/155) and $19 \%$ after $(27 / 142)$ calculator implementation; or loading dose and first maintenance dose are both incorrect: $37.4 \%$ before $(58 / 155)$ and $13.4 \%$ after (19/142) calculator implementation (table 5 ).

Table 3 Analysis of the accuracy of gentamicin initial doses

\begin{tabular}{|c|c|c|c|c|c|}
\hline Category & $\begin{array}{l}\text { Before (\%) } \\
n=195\end{array}$ & $\begin{array}{l}\text { After (\%) } \\
n=215\end{array}$ & OR & $95 \% \mathrm{Cl}$ & p Value \\
\hline Correct dose & 75 (38.5) & $120(55.8)$ & 2.02 & 1.36 to 3.00 & $<0.001$ \\
\hline Overdose & $83(42.6)$ & 62 (28.8) & 0.55 & 0.36 to 0.82 & 0.004 \\
\hline Underdose & $37(19.0)$ & 33 (15.3) & 0.77 & 0.46 to 1.30 & 0.331 \\
\hline
\end{tabular}


Table 4 Analysis of the accuracy of vancomycin initial doses

\begin{tabular}{|c|c|c|c|c|c|}
\hline Category & $\begin{array}{l}\text { Before (\%) } \\
\mathrm{n}=155\end{array}$ & $\begin{array}{l}\text { After (\%) } \\
n=142\end{array}$ & OR & $95 \% \mathrm{Cl}$ & p Value \\
\hline \multicolumn{6}{|l|}{ Loading dose } \\
\hline Correct dose & 65 (41.9) & $96(67.6)$ & 2.89 & 1.80 to 4.65 & $<0.001$ \\
\hline Overdose & $5(3.2)$ & $5(3.5)$ & 1.10 & 0.31 to 3.86 & 0.888 \\
\hline Underdose & $85(54.8)$ & 41 (28.9) & 0.33 & 0.21 to 0.54 & $<0.001$ \\
\hline \multicolumn{6}{|c|}{ First maintenance dose } \\
\hline Correct dose & $69(44.5)$ & 95 (66.9) & 2.52 & 1.57 to 4.04 & $<0.001$ \\
\hline Overdose & $56(36.1)$ & 32 (22.5) & 0.51 & 0.31 to 0.86 & 0.010 \\
\hline Underdose & $30(19.4)$ & 15 (10.6) & 0.49 & 0.25 to 0.96 & 0.037 \\
\hline \multicolumn{6}{|c|}{ Initiation regimen (both loading and first maintenance doses) } \\
\hline Correct & 37 (23.9) & 68 (47.9) & 2.93 & 1.79 to 4.81 & $<0.001$ \\
\hline Incorrect & $118(76.1)$ & 74 (52.1) & 0.34 & 0.21 to 0.56 & $<0.001$ \\
\hline
\end{tabular}

A subanalysis was undertaken for patients at higher risk including elderly ( $\geq 65$ years), renally-impaired $(\mathrm{CrCl}<60 \mathrm{~mL} / \mathrm{min})$ and obese $\left(\mathrm{BMI} \geq 30 \mathrm{~kg} / \mathrm{m}^{2}\right)$. No significant differences in the rate of gentamicin correct doses before and after the calculator implementation were found between elderly (14, 31.1\% and 31, 68.9\%) and non-elderly $(61,40.7 \%$ and $89,59.3 \%)$ patients $(p=0.248)$, patients with $(13,35.1 \%$ and $24,64.9 \%)$ and without $(62,39.2 \%$ and $96,60.8 \%)$ renal impairment $(\mathrm{p}=0.644)$, or obese $(17,43.6 \%$ and $22,56.4 \%)$ and nonobese $(58,37.2 \%$ and $98,62.8 \%)$ patients $(\mathrm{p}=0.462)$. There were also no significant differences in the rate of vancomycin correct regimens before and after the calculator between elderly $(9,38.9 \%$ and $24,61.1 \%)$ and non-elderly (28, 27.3\% and 44, 72.7\%) patients $(\mathrm{p}=0.247)$, patients with $(6,46.2 \%$ and $7,53.8 \%)$ and without $(31,33.7 \%$ and $61,66.3 \%)$ renal impairment $(\mathrm{p}=0.379)$, or obese $(5,20 \%$ and $20,80 \%)$ and non-obese $(32,40 \%$ and $48,60 \%)$ patients $(\mathrm{p}=0.068)$.

\section{DISCUSSION}

The initial dose accuracy for both gentamicin and vancomycin significantly improved after implementation of new calculators providing CDS to prescribers at an NHS teaching hospital. Incorrect initial doses of gentamicin were reduced from $61.5 \%$ to $44.2 \%$ ( $\mathrm{p}<0.001)$. Incorrect loading doses of vancomycin were reduced from $58.1 \%$ to $32.4 \% \quad(p<0.001)$, while incorrect first maintenance doses were reduced from $55.5 \%$ to $33.1 \%$ $(\mathrm{p}<0.001)$. Incorrect vancomycin initiation regimens were reduced from $76.1 \%$ to $52.1 \%(\mathrm{p}<0.001)$. The calculator pages on the hospital intranet were frequently accessed in the postcalculator phase. The activities undertaken to promote the calculators and make them compatible with the electronic prescribing system are anticipated to have a role in such access.

Different CDS tools have shown improvements in gentamicin and vancomycin dosing. A previous UK study found that introducing an online gentamicin dose calculator led to a $300 \%$ improvement in dosing accuracy $(30 \%, 15 / 50$ precalculator to $92 \%, 46 / 50$ postcalculator) at an NHS hospital. The calculator in this study required the same data as the current study (ie, gender, age, weight, height, $\mathrm{SrCr}$ ) to provide the correct dose. Prophylactic doses were also excluded from the study. ${ }^{17}$ However, it was conducted only on surgical wards, had a relatively small sample size (only 50 patients in each phase) and no statistical analysis was conducted. Another study conducted in Taiwan investigated the impact of an online gentamicin dose calculator incorporated into the hospital CPOE system, using a pharmacokinetic formula to provide the correct dose. The main outcome measure was the number of gentamicin orders that resulted in undesirable serum levels. The calculator reduced undesirable levels from $32.7 \%$ (152/465) to $13.5 \%$ (40/297). ${ }^{18}$ Nevertheless, the study was conducted only in intensive care units and used a compound pharmacokinetic equation, which might be more suitable only for specific patient groups. In addition, no statistical analysis was performed.

A US study by Frankel $e t a l^{19}$ showed an improvement in initial vancomycin dosing at the ED after the

Table 5 Subanalysis of the accuracy of vancomycin initiation regimens

\begin{tabular}{|c|c|c|c|c|c|}
\hline Category & $\begin{array}{l}\text { Before (\%) } \\
n=155\end{array}$ & $\begin{array}{l}\text { After (\%) } \\
n=142\end{array}$ & OR & $95 \% \mathrm{Cl}$ & p Value \\
\hline LD correct and MD correct & $37(23.9)$ & $68(47.9)$ & 2.93 & 1.79 to 4.81 & $<0.001$ \\
\hline LD correct and MD incorrect & $28(18.1)$ & 28 (19.7) & 1.11 & 0.62 to 1.99 & 0.716 \\
\hline LD incorrect and MD correct & $32(20.6)$ & 27 (19.0) & 0.90 & 0.51 to 1.60 & 0.725 \\
\hline LD incorrect and MD incorrect & $58(37.4)$ & $19(13.4)$ & 0.26 & 0.14 to 0.46 & $<0.001$ \\
\hline
\end{tabular}


introduction of CPOE with vancomycin weight-based orders. The CPOE doses showed 51.1\% (120/235) compliance to the recommended initial dosing guideline compared with $34.9 \%$ in the pre-CPOE doses $(82 / 235$, $\mathrm{p}<0.001)$. Compared to the vancomycin calculator in the current study, this CPOE was only valid for loading doses since it did not adjust doses for height or $\mathrm{CrCl}$, and it was examined only in the ED. The 'Pharmacist-to-Dose' intervention in the Vincent $e t a l^{7}$ study showed a significant reduction in aminoglycoside and vancomycin dosing errors. However, the study had a relatively small sample size (49 patients preintervention and 48 postintervention) and lacked details on how many correct and incorrect doses were associated with each drug (only combined data were provided). The intervention by Roberts $e t a l^{8}(\mathrm{GFR}+)$ also reduced dosing errors with gentamicin and vancomycin. However, the reduction in vancomycin errors was not statistically significant $(p=0.07)$. The number of patients in each group was relatively small (73 pre-GFR+ and 38 post-GFR+ for gentamicin and 34 pre-GFR+ and 17 post-GFR+ for vancomycin). Moreover, the study used a modified version of Cockcroft-Gault equation that caps $\mathrm{SrCr}$ to a minimum of $60 \mu \mathrm{mol} / \mathrm{L}$ and also a complex gentamicin dosing model that was derived from local population kinetics, which limits the generalisability of its findings.

The vast majority of incorrect vancomycin loading doses in the current study were underdoses $(94.4 \%$, $85 / 90)$. Similarly, $90.8 \%(3143 / 3461)$ of incorrect vancomycin doses in the Fuller $e t a t^{6}$ study were underdoses. Although actual BW is the ideal method for calculating initial vancomycin doses, a fixed dose of $1000 \mathrm{mg}$ is commonly used in the ED. ${ }^{20}$ Most patients in a US study conducted in the ED $(87.5 \%, 210 / 240)$ were administered an initial vancomycin dose of $1000 \mathrm{mg} .{ }^{20}$ In the current study, $1000 \mathrm{mg}$ dose was used in $40.4 \%$ of all loading doses (120/297), $75.8 \%(91 / 120)$ of them were underdoses, which shows that this practice is not common only at the ED. The use of $1000 \mathrm{mg}$ loading doses was significantly reduced from $52.3 \%$ (81/155) before to $27.5 \%(39 / 142)$ after implementation of the calculator $(p<0.001)$. However, the extent of underdosing here was relatively unchanged from $79 \%$ before to $69.2 \%$ after the intervention. Likewise, the study by Frankel et $a l^{19}$ identified that initial doses of $1000 \mathrm{mg}$ vancomycin were prescribed in 206/235 $(87.7 \%$ ) of cases and $72.3 \%$ of these were underdoses. Following implementation of CPOE, that rate of prescribing of $1000 \mathrm{mg}$ doses fell to $128 / 235$ (54.5\%), of which $59.4 \%$ were underdoses. The current study was the first to assess first maintenance dose as part of the initial dose of vancomycin in addition to loading dose, so no comparison with past studies is possible.

The introduction of CDS tools into healthcare is a complex interaction between people, technology and organisational workflow. The automatic provision of CDS tools as part of the clinician workflow is seen as the most important element for successful CDS implementation. ${ }^{8}$
In this study, efforts were made to incorporate the use of calculators into the prescriber workflow by adding a direct link to them from EPMA and setting an instruction to use them on the electronic prescription forms. However, further work is required to fully integrate these calculators into the electronic prescribing system (eg, automatic population of appropriate patient demographic data and laboratory results). The reported advantages of CDS tools in optimising drug dosing may cause physicians to over-rely on their suggestions. However, prescribers should always be careful when using CDS tools, particularly for prescribing high-risk and narrowtherapeutic-index medications, as studies have highlighted that these tools may lead to unintended negative results. ${ }^{9} 2122$

One limitation of this study is that it was not possible, due to technical barriers, to identify whether visitors to the calculator pages actually used the tools to aid prescribing. Therefore, the improvements in gentamicin and vancomycin initial-dose accuracy cannot be definitively linked to the use of the calculators, and so further work should be undertaken to link visits to these calculators to actual patient dosing. However, the significant improvements in dose accuracy after implementation of the calculators provide an indication that they contributed to this improvement, especially as no other proactive initiatives to improve gentamicin and vancomycin dosing took place during the same period. In addition, gentamicin and vancomycin dosing guidance was the same preintervention and postintervention. Prospective data collection would have been the ideal method to collect data in the precalculator and postcalculator phases. As this was not feasible, the use of a retrospective method to collect data and a different source to identify patients (ie, Microbiology database) in the precalculator phase was considered a limitation of this study. Selection of the precalculator study population differed from that associated with the postcalculator intervention group. The population in the precalculator phase was retrospectively identified from records of patients who had been prescribed gentamicin or vancomycin during an 8-month period and for whom a serum level had been requested. However, the postcalculator group was identified prospectively over a 2-month period using an antimicrobial filter within EPR to identify all active prescriptions for gentamicin and vancomycin, regardless of whether a serum level had been requested. The differences in these methodologies may have resulted in different patient and prescriber groups, which may have had an impact on the findings of this study. However, this impact is likely minimal. The guidelines for gentamicin and vancomycin prescribing applied across all patient groups included in the study. Where local specialty-specific guidelines for gentamicin and vancomycin were in place (eg, continuous vancomycin infusions in critical care), these prescriptions and patients were excluded from the study. The precalculator data had to be collected retrospectively due to the unavailability of EPMA on all hospital wards at that 
time. Moreover, the calculators were already available online, although not promoted or linked with EPMA, when the decision to conduct the study was taken. Thus, the retrospective-review dates (1 January 2011-31 August 2011) were chosen before the date calculators were first available online. The Microbiology database was the only source available to retrospectively identify patients prescribed gentamicin and vancomycin.

There were some differences in demographics precalculators and postcalculators, including patient gender in the gentamicin group, $\mathrm{BMI}$ and $\mathrm{CrCl}$ in the vancomycin group, and prescriber specialty in both groups. These differences are probably due to the different data collection methods used, but it is not anticipated that they affected the overall results. The comparison between high-risk and non-high-risk patients showed that age, weight and renal function did not affect the dosing accuracy. In addition, the differences in specialty rates are unlikely to have affected the overall outcomes because the number of correct doses in the specialty with the highest number of patients (Haematology/ Oncology in the gentamicin group and Medicine in the Vancomycin group) was higher postcalculator, although the overall proportion of doses was higher or similar precalculator.

Data from the literature show that giving the correct dose of gentamicin or vancomycin improves clinical outcomes. A Scottish study showed that cure rate was higher in patients for whom the gentamicin dose was given according to protocol $(95.7 \%, 22 / 23)$ compared to those for whom it was not $(75 \%, 24 / 32), p=0.06$. Less toxicity was observed in patients for whom the doses were adjusted according to protocol $(4.3 \%, 1 / 23$ vs $28.1 \%, 9 / 32, \quad \mathrm{p}<0.05) .{ }^{23}$ Fuller et $a t^{6}$ demonstrated that patients who received a vancomycin overdose $(>20 \mathrm{mg} / \mathrm{kg})$ stayed in hospital longer $(\mathrm{p}=0.005)$, were more likely to spend $\geq 3$ days in hospital $(\mathrm{OR}=1.49$, $\mathrm{p}=0.006)$ and more likely to die $(\mathrm{OR}=1.88, \mathrm{p}=0.004)$. They also showed that correct doses were associated with significantly higher numbers of therapeutic serum levels (21.6\% vs $14.3 \%, \mathrm{p}=0.004)$. However, this study did not assess the independency of the association between these outcomes and vancomycin overdoses. With the exception of one study, which showed a reduction in undesirable serum levels with the intervention, ${ }^{18}$ none of the intervention studies discussed above have assessed patient clinical outcomes. Since this study focused on identifying the accuracy of prescribing gentamicin and vancomycin initial doses according to an evidence-based guideline, it did not assess the difference in patient clinical outcomes between precalculator and postcalculator doses (eg, correct serum level, treatment-success rate). The aim of treatment with these drugs is to administer safe initial doses to ensure prompt, effective treatment of potentially life-threatening infections while minimising the risk of toxicity. Ensuring first doses are accurately calculated is the first stage of safe, effective treatment. The assessment of serum levels after subsequent doses to exclude toxicity, and resolution of infection, are subject to many patient and process variables and were beyond the scope of this study. However, further work would be needed to assess the direct impact of this intervention on patient clinical outcomes. As the postcalculator phase was conducted directly after completing the calculators' implementation, the dosing accuracy and calculators' usage should be reassessed after 12-24 months to evaluate the long-term impact of the calculators.

\section{CONCLUSION}

This study suggests that gentamicin and vancomycin dose calculators significantly improved the prescribing of initial doses of these agents. Healthcare organisations implementing electronic prescribing systems should consider including such CDS tools in their programmes to support the prescribing of these high-risk drugs. However, this study did not assess the long-term impact of the calculators and their clinical outcomes. Therefore, further work is needed to evaluate the prolonged effect of these calculators, and to determine the association between their use and improvement of clinical outcomes.

Acknowledgements The authors appreciate the invaluable help provided by James Godfrey and Clive Barnfather in giving access to drug serum levels from the Microbiology database, Mimoza Neziri in giving access to paper patient records in the study's retrospective phase, Hardeep Sahota in giving access to the electronic filter for antimicrobial prescriptions, Peter Hughes in copresenting the Grand-Round presentation and Liam Slater in providing data on the visits to the calculator pages on the hospital intranet.

Contributors $\mathrm{AH}$ was the principal author of the manuscript, collected and analysed the data and presented the work at the hospital Grand Round. GC facilitated the project through liaison with colleagues within Pharmacy and in other hospital departments. JH liaised with the electronic prescribing team and prescribers to promote the online calculators. CW, GC, JH and PW participated in the design of the study, advised on the analysis and presentation of results, and provided critical feedback to the manuscript.

Funding AH received a scholarship from Hamad Medical Corporation, Qatar, to undertake this postgraduate research.

Competing interests None declared.

Ethics approval The hospital Clinical Audit and Effectiveness Department.

Provenance and peer review Not commissioned; externally peer reviewed.

Data sharing statement No additional data are available.

Open Access This is an Open Access article distributed in accordance with the Creative Commons Attribution Non Commercial (CC BY-NC 4.0) license, which permits others to distribute, remix, adapt, build upon this work noncommercially, and license their derivative works on different terms, provided the original work is properly cited and the use is non-commercial. See: http:// creativecommons.org/licenses/by-nc/4.0/

\section{REFERENCES}

1. Joint Formulary Committee. British national formulary. 66th edn. London: British Medical Association and Royal Pharmaceutical Society, 2013.

2. Lesar TS, Briceland L, Stein DS. Factors related to errors in medication prescribing. JAMA 1997;277:312-17.

3. Leong CL, Buising K, Richards M, et al. Providing guidelines and education is not enough: an audit of gentamicin use at The Roya Melbourne Hospital. Intern Med J 2006;36:37-42. 
4. Martin J, Barras M, Yui NA, et al. Gentamicin monitoring practices in teaching hospitals - time to undertake the necessary randomised controlled trial. J Clin Toxicol 2012;2:

5. Swartling M, Gupta R, Dudas V, et al. Short term impact of guidelines on vancomycin dosing and therapeutic drug monitoring Int J Clin Pharm 2012;34:282-5.

6. Fuller BM, Mohr N, Skrupky L, et al. Emergency department vancomycin use: dosing practices and associated outcomes. J Emerg Med2013;44:910-18.

7. Vincent W, Martin C, Winstead P, et al. Effects of a pharmacistto-dose computerized request on promptness of antimicrobial therapy. J Am Med Inform Assoc 2009;16:47-53.

8. Roberts $G$, Farmer C, Cheney $P$, et al. Clinical decision support implemented with academic detailing improves prescribing of key renally cleared drugs in the hospital setting. J Am Med Inform Assoc 2010;17:308-12.

9. Eslami S, Abu-Hanna A, de Keizer N, et al. Errors associated with applying decision support by suggesting default doses for aminoglycosides. Drug Saf 2006;29:803-9.

10. Hamad A, Cavell G, Wade P, et al. Risk of medication safety incidents with antibiotic use measured by defined daily doses. Int J Clin Pharm 2013;35:772-9.

11. Antibiotic Usage Steering Group. Adult pocket antimicrobial guide. 6th edn. London: King's College Hospital NHS Foundation Trust, 2010.

12. Cockcroft DW, Gault MH. Prediction of creatinine clearance from serum creatinine. Nephron 1976;16:31-41.

13. Scottish Intercollegiate Guidelines Network. Diagnosis and management of chronic kidney disease: a national clinical guideline. Edinburgh: Scottish Intercollegiate Guidelines Network, 2008.
14. Devine BJ. Gentamicin therapy. Drug Intell Clin Pharm 1974:8:650-5.

15. Schwartz SN, Pazin GJ, Lyon JA, et al. A controlled investigation of the pharmacokinetics of gentamicin and tobramycin in obese subjects. J Infect Dis 1978;138:499-505.

16. Thomson $\mathrm{AH}$, Staatz CE, Tobin CM, et al. Development and evaluation of vancomycin dosage guidelines designed to achieve new target concentrations. J Antimicrob Chemother 2009;63:1050-7.

17. Qureshi I, Habayeb H, Grundy C. Improving the correct prescription and dosage of gentamicin. BMJ Qual Improv Rep 2012;1.

18. Chan AL, Wang HY, Leung HW. Incorporation of a gentamicin dosage calculator into a computerized prescriber-order-entry system. Am J Health Syst Pharm 2006;63:1344-5.

19. Frankel KC, Rosini JM, Levine BJ, et al. Computerized provider order entry improves compliance of vancomycin dosing guidelines in the emergency department. Am J Emerg Med 2013;31:1715-16.

20. Rosini JM, Grovola MR, Levine BJ, et al. Prescribing habits of vancomycin in the emergency department: are we dosing appropriately? J Emerg Med 2013;44:979-84.

21. Ash JS, Sittig DF, Campbell EM, et al. Some unintended consequences of clinical decision support systems. AMIA Annu Symp Proc 2007;26-30.

22. Koppel R, Metlay JP, Cohen A, et al. Role of computerized physician order entry systems in facilitating medication errors. JAMA 2005;293:1197-203.

23. Buabeng KO, Mackenzie AR, Laing RB, et al. Assessment of the efficacy, safety and quality of gentamicin use in Aberdeen Royal Infirmary. J Antimicrob Chemother 1999;44:843-5. 